\title{
Understanding the Role of Poly(vinylpyrrolidone) in Stabilizing and Capping Colloidal Silver Nanocrystals
}

Tung-Han Yang, Jaewan Ahn, Shi Shi, and Dong Qin*

School of Materials Science and Engineering, Georgia Institute of Technology, Atlanta, Georgia 30332, United States

*Corresponding author: dong.qin@mse.gatech.edu

Keywords: poly(vinylpyrrolidone), quality of solvent, polymer-solvent interaction, silver nanocrystals, surface-enhanced Raman scattering 

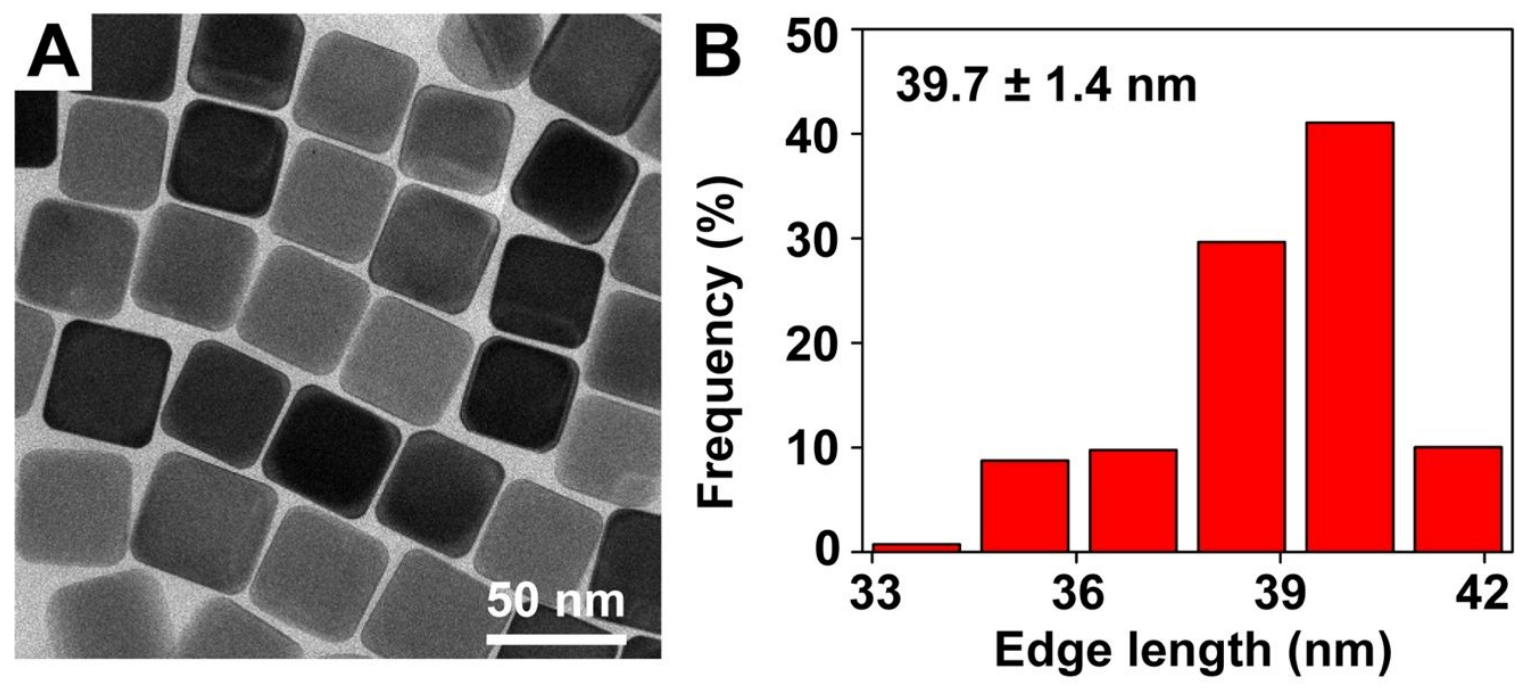

Figure S1. (A) TEM image of the PVP-capped Ag nanocubes used in the present study and (B) a histogram of the particle size distribution, which gives an average edge length of $39.7 \pm 1.4 \mathrm{~nm}$. 


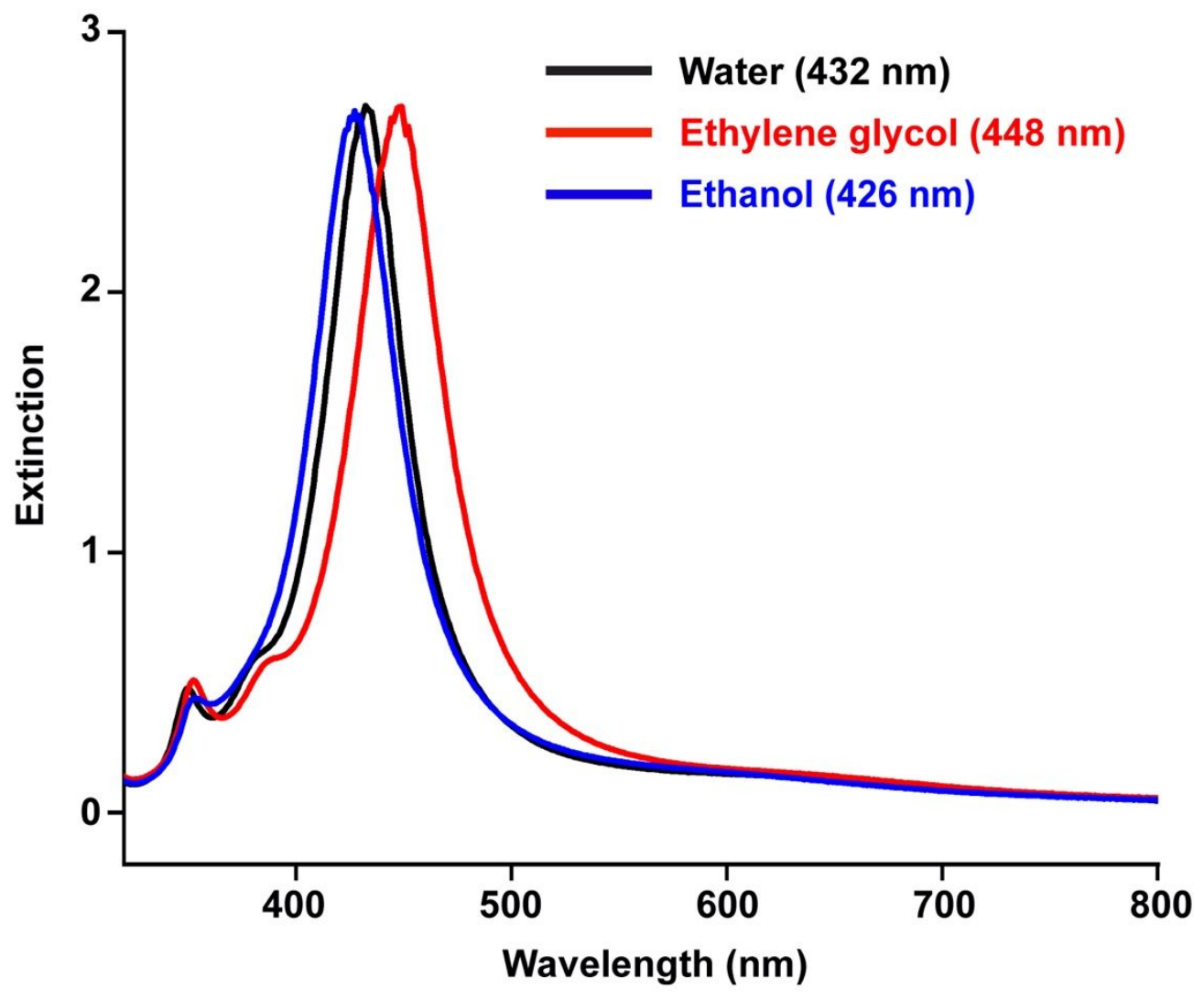

Figure S2. UV-vis spectra of the same batch of PVP-capped Ag nanocubes when dispersed in water, ethylene glycol (EG), and ethanol, respectively. 


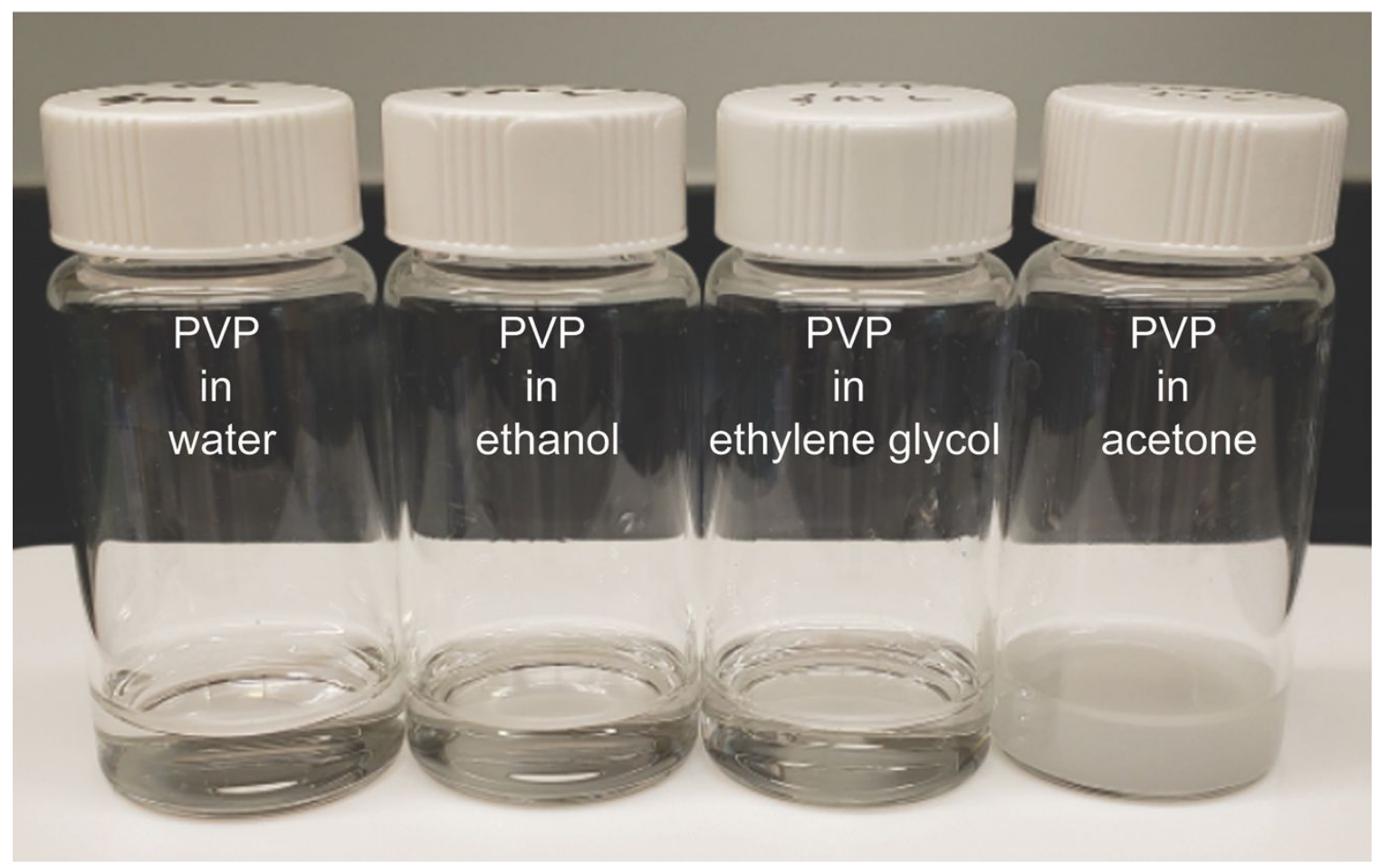

Figure S3. Photos of vials containing $3 \mathrm{~mL}$ of PVP solution in water, ethanol, ethylene glycol (EG), and acetone, respectively. Each solution was prepared by adding $70 \mathrm{mg}$ of PVP55k into 3.5 $\mathrm{mL}$ of the solvent under magnetic stirring for $30 \mathrm{~min}$. 


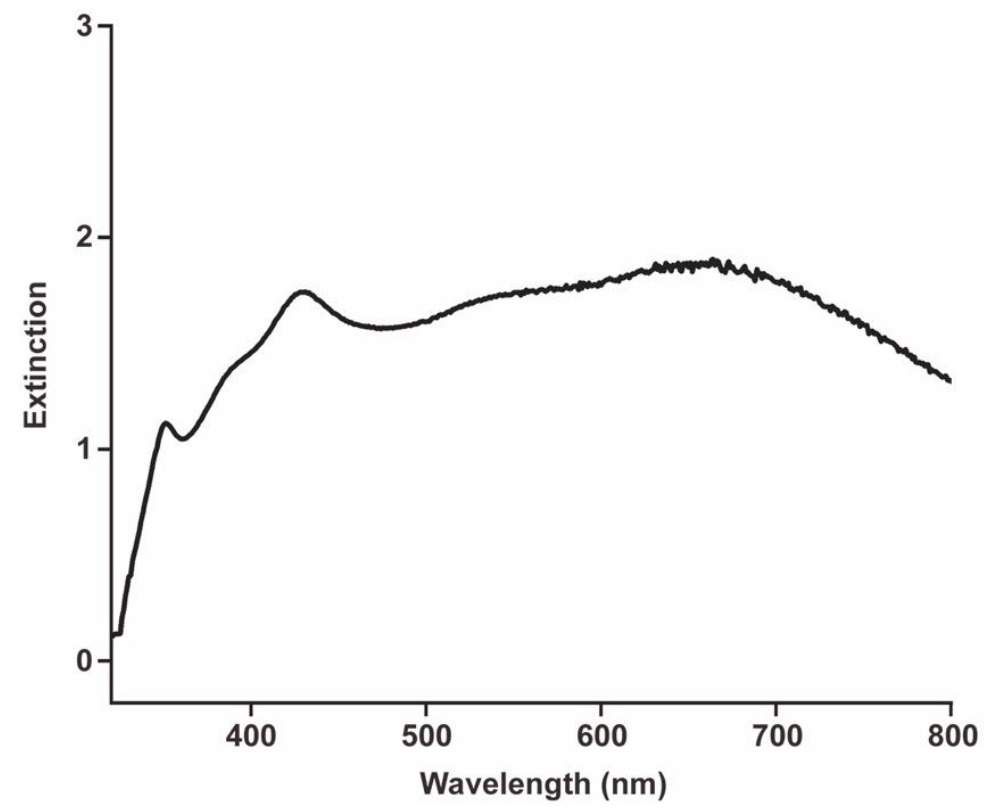

Figure S4. UV-vis spectrum of the PVP-capped Ag nanocubes when dispersed in acetone. 

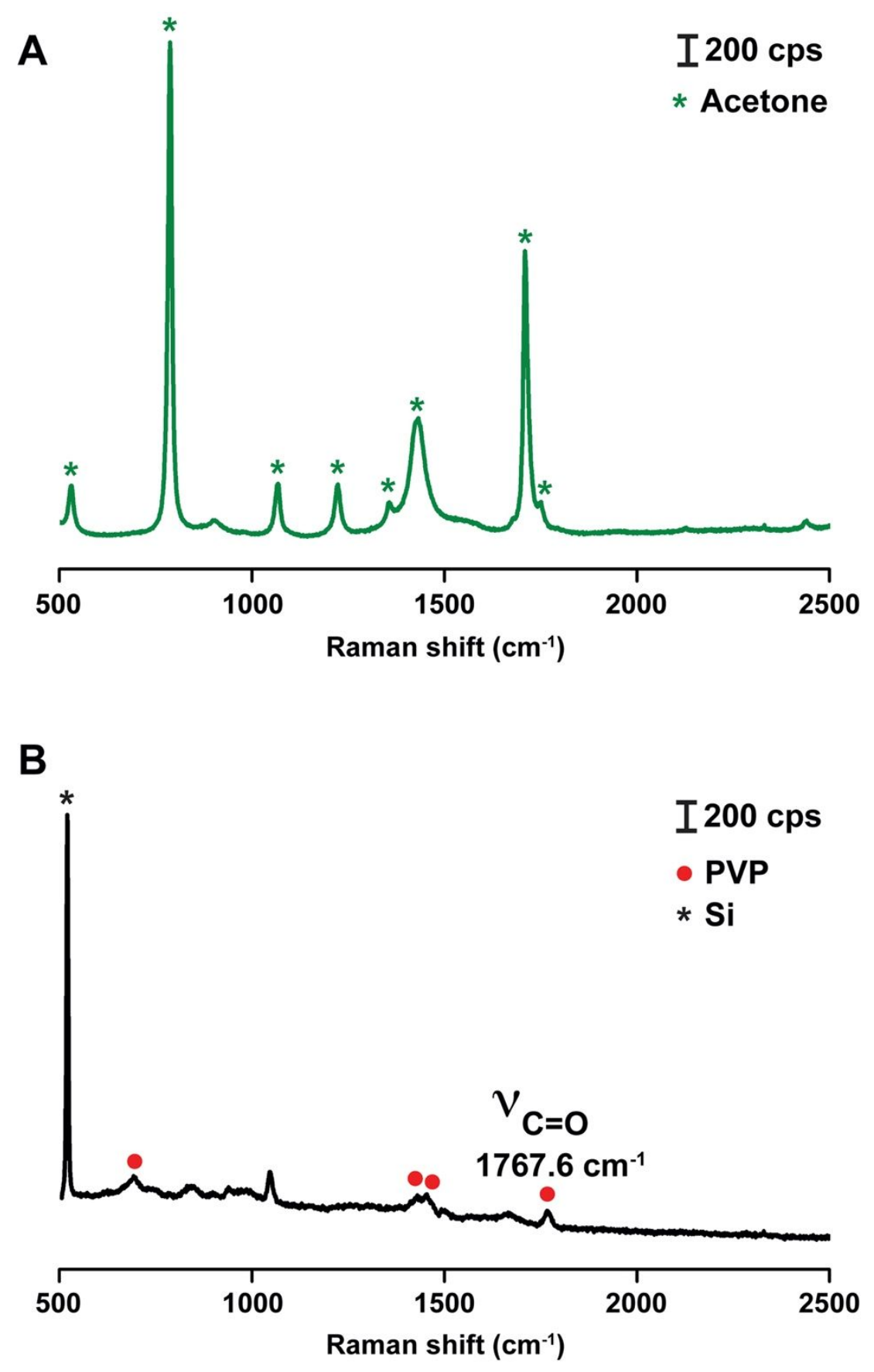

Figure S5. (A) SERS spectrum recorded from the PVP-capped Ag nanocubes dispersed in acetone. (B) SERS spectrum recorded from the PVP-capped Ag nanocubes deposited on a Si wafer. 




B

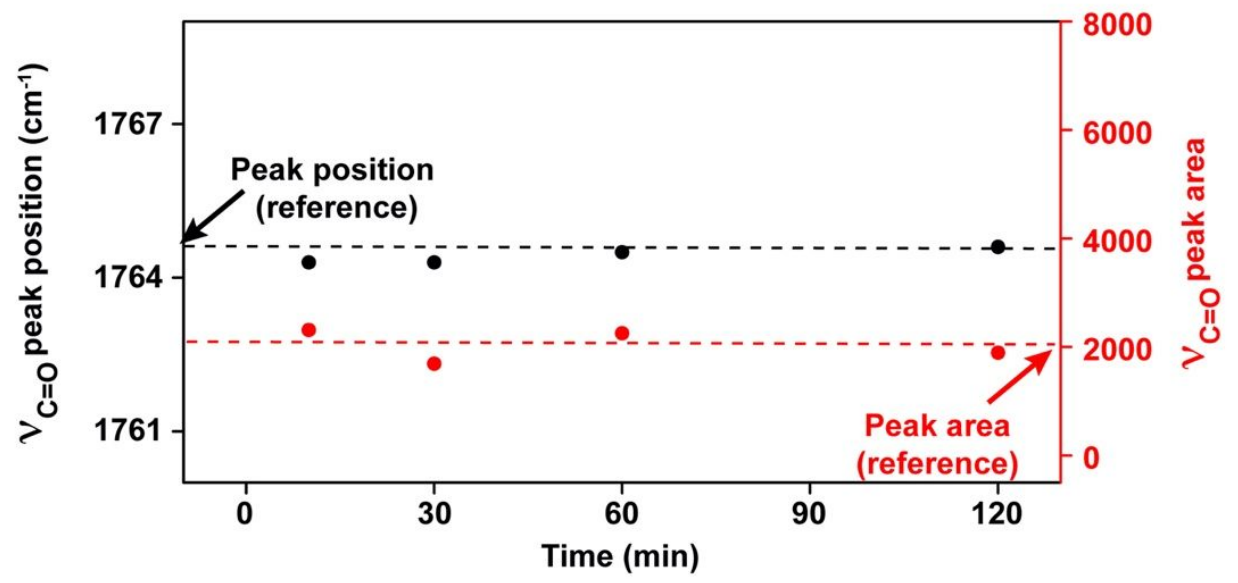

Figure S6. (A) SERS spectra recorded at different time points after introducing $30 \mu \mathrm{L}$ of the aqueous suspension of the PVP-capped Ag nanocubes into $270 \mu \mathrm{L}$ of PVP solution in ethylene glycol (EG) at a concentration of $3.84 \mathrm{mg} / \mathrm{mL}$. The reference SERS spectrum was collected from a sample obtained by mixing $30 \mu \mathrm{L}$ of the aqueous suspension of the PVP-capped Ag nanocubes with $270 \mu \mathrm{L}$ of EG and waiting for $30 \mathrm{~min}$. (B) Plots of peak position and area for the $v_{\mathrm{C}=\mathrm{O}}$ band of PVP at different time points and those of the reference sample. 
A

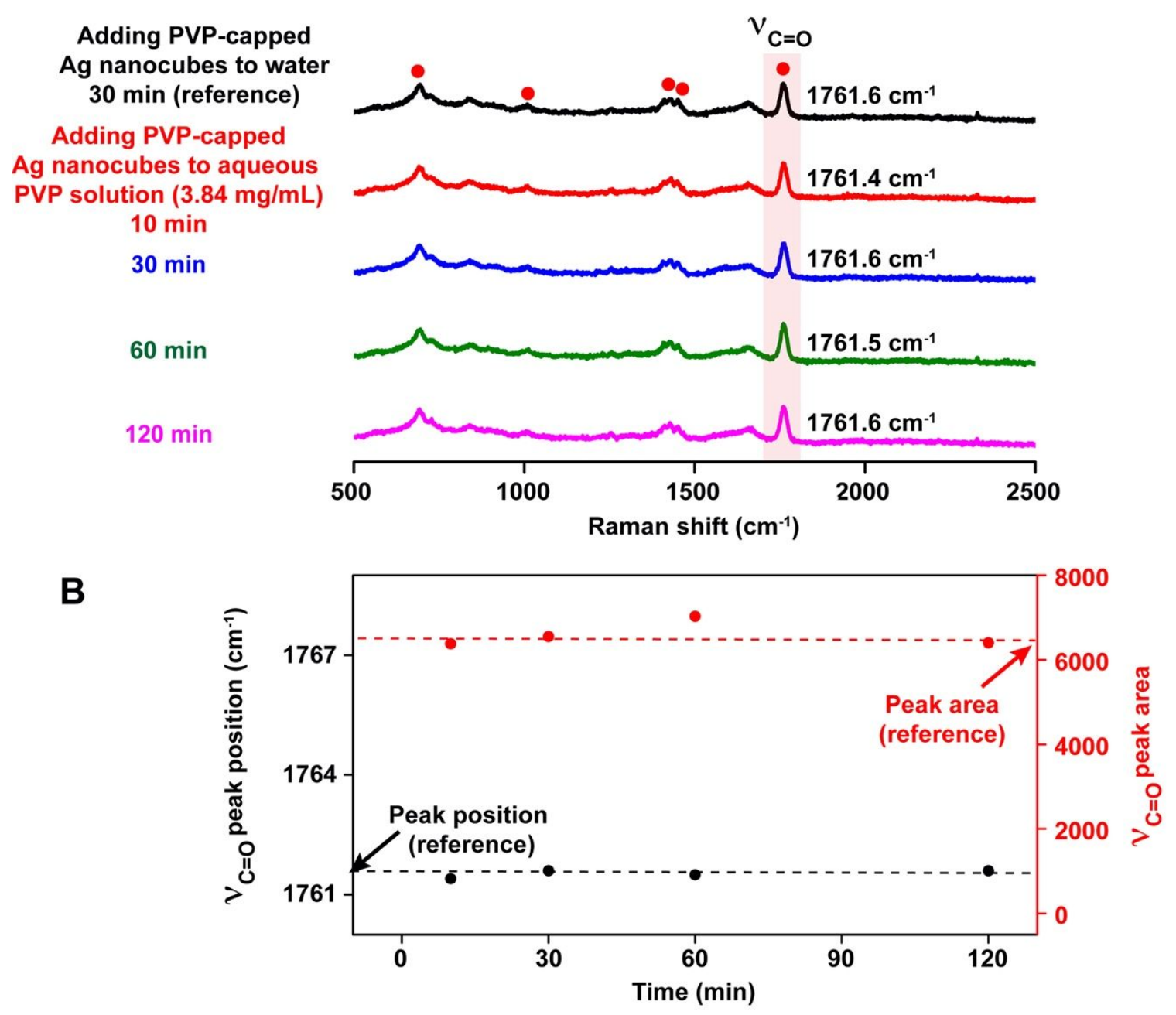

Figure S7. (A) SERS spectra recorded at different time points after introducing $30 \mu \mathrm{L}$ of the aqueous suspension of the PVP-capped Ag nanocubes into $270 \mu \mathrm{L}$ of aqueous PVP solution at a concentration of $3.84 \mathrm{mg} / \mathrm{mL}$. The reference SERS spectrum was collected from a sample obtained by mixing $30 \mu \mathrm{L}$ of the aqueous suspension of the PVP-capped Ag nanocubes with $270 \mu \mathrm{L}$ of water and waiting for $30 \mathrm{~min}$. (B) Plots of peak position and area for the $v_{\mathrm{C}=\mathrm{O}}$ band of PVP at different time points and those of the reference sample. 


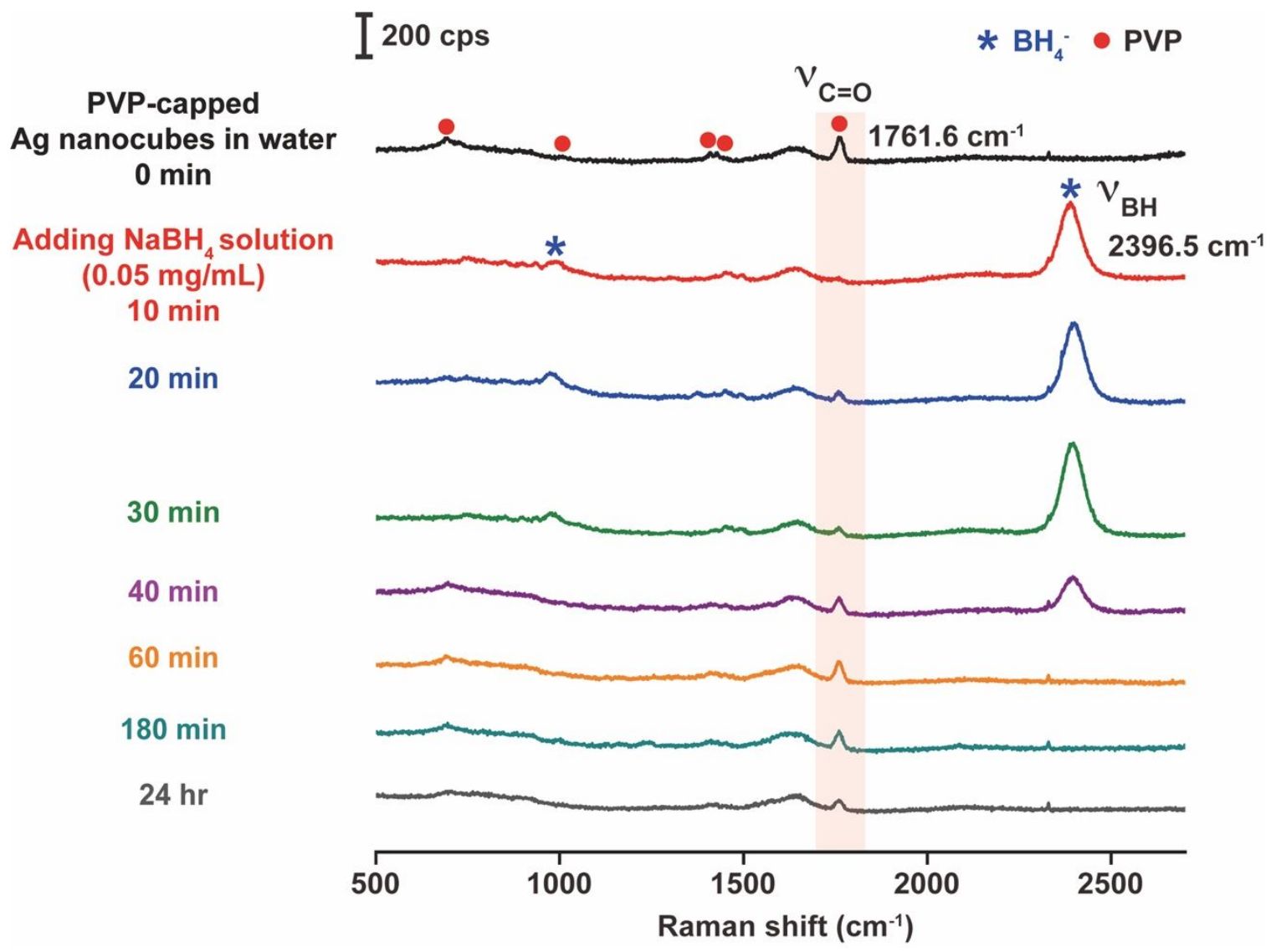

Figure S8. SERS spectra recorded from an aqueous suspension of the PVP-capped Ag nanocubes before and after the addition of aqueous $\mathrm{NaBH}_{4}$ solution to attain a final concentration of 0.05 $\mathrm{mg} / \mathrm{mL}$. 


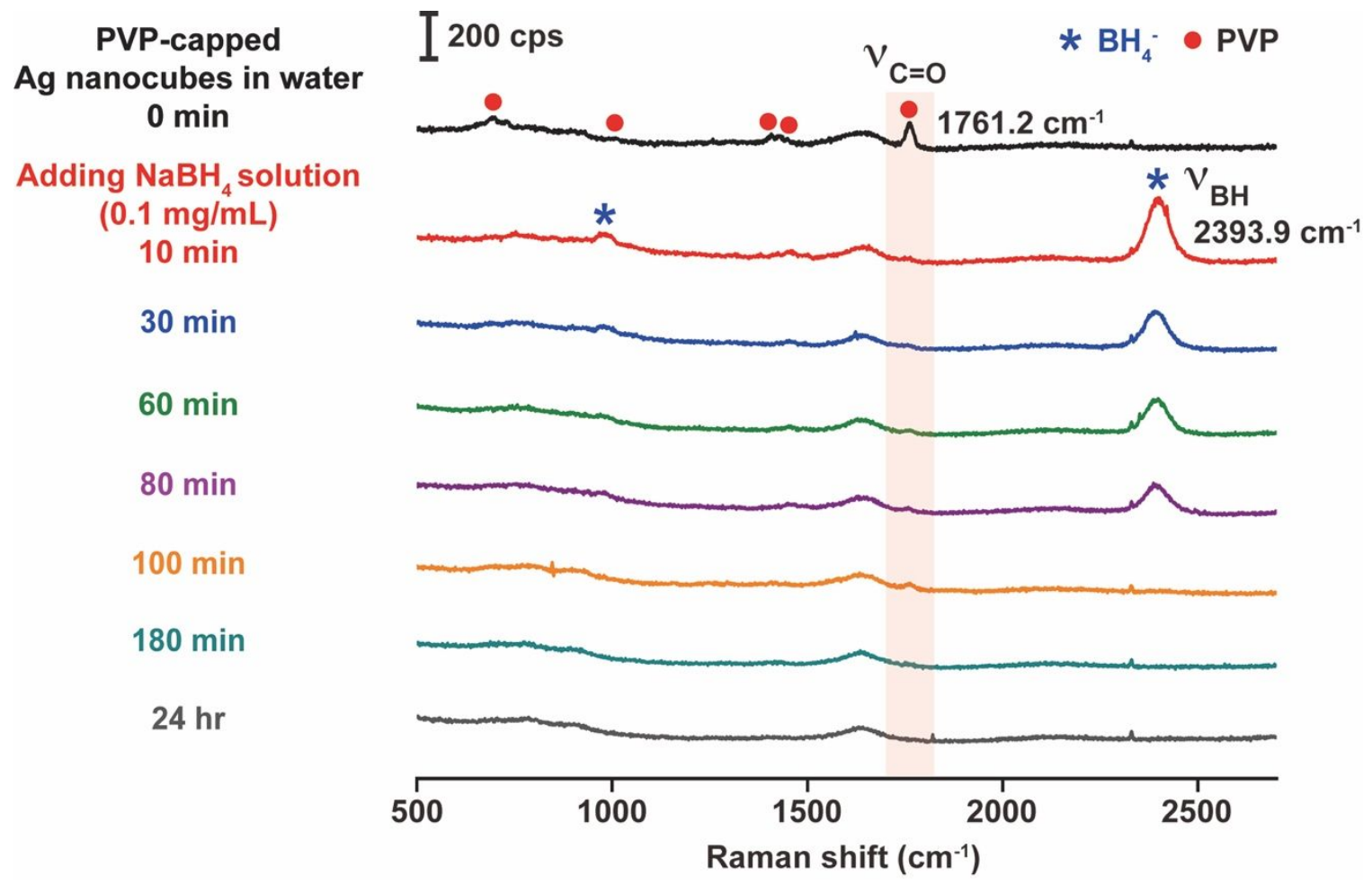

Figure S9. SERS spectra recorded from an aqueous suspension of the PVP-capped Ag nanocubes before and after the addition of aqueous $\mathrm{NaBH}_{4}$ solution to attain a final concentration of 0.1 $\mathrm{mg} / \mathrm{mL}$. 
Table S1. A summary of the measured Raman peak of $\operatorname{Si}(100)$ at $520.18 \mathrm{~cm}^{-1}$, which served as a standard for the calibration of Raman shift. The measurements were conducted over a period of about one month. The standard deviation is $0.15 \mathrm{~cm}^{-1}$.

\begin{tabular}{|c|c|c|c|}
\hline$\#$ & Center $\left(\mathrm{cm}^{-1}\right)$ & Height & Area \\
\hline 1 & 520.12 & 104999 & 1045450 \\
\hline 2 & 520.43 & 102243 & 1017190 \\
\hline 3 & 520.07 & 104812 & 911853 \\
\hline 4 & 520.11 & 99118 & 1064540 \\
\hline 5 & 520.51 & 114639 & 1073180 \\
\hline 6 & 520.16 & 106627 & 1014280 \\
\hline 7 & 520.09 & 102069 & 966867 \\
\hline 8 & 520.11 & 100514 & 930536 \\
\hline 9 & 520.13 & 99268 & 1043200 \\
\hline 10 & 520.11 & 108823 & 1005477 \\
\hline Mean & 520.18 & 104311 & 55274 \\
\hline & 0.15 & & \\
\hline & & & \\
\hline
\end{tabular}

